\title{
Paper-based microfluidic sampling and separation of analytes for potentiometric ion sensing
}

\author{
Jiawang Ding ${ }^{\mathrm{a}, \mathrm{b}}$, Ning He ${ }^{\mathrm{b}}$, Grzegorz Lisak ${ }^{\mathrm{b}, \mathrm{c}, \mathrm{d}}$, Wei Qin ${ }^{\mathrm{a}}$, Johan Bobacka ${ }^{\mathrm{b}, *}$ \\ ${ }^{a}$ Key Laboratory of Coastal Environmental Processes and Ecological Remediation, Yantai Institute of Coastal Zone Research (YIC), Chinese Academy of \\ Sciences (CAS); Shandong Provincial Key Laboratory of Coastal Environmental Processes, YICCAS, Yantai, Shandong 264003, PR China \\ ${ }^{\mathrm{b}}$ Åbo Akademi University, Johan Gadolin Process Chemistry Centre, Laboratory of Analytical Chemistry, Biskopsgatan 8, FIN-20500 Turku/Åbo, Finland \\ c School of Civil and Environmental Engineering, Nanyang Technological University, 50 Nanyang Avenue, Singapore 639798, Singapore \\ ${ }^{\mathrm{d}}$ Nanyang Environment and Water Research Institute, 1 Cleantech Loop, CleanTech, Singapore 637141, Singapore
}

\section{A R T I C L E I N F O}

\section{Article history:}

Received 27 September 2016

Received in revised form

22 November 2016

Accepted 23 November 2016

Available online 27 November 2016

\section{Keywords:}

Potentiometry

Ion-selective electrodes

Paper-based sampling

Paper-based separation

Chloride

Salicylate

\begin{abstract}
A B S T R A C T
This work demonstrates a paper-based microfluidic sampling and separation platform that allows potentiometric sensing of chloride ions in presence of strongly interfering salicylate ions using a solid-contact ion-selective electrode as a detector. The device was composed of two pieces of paper with different shapes and pore sizes. A "T" shaped filter paper with a pore size of $12-25 \mu \mathrm{m}$ was used as the detection zone. A filter paper with a pore size of $2.0 \mu \mathrm{m}$ was modified with a complexing agent $\left(\mathrm{Fe}^{3+}\right)$ and served as the separation zone. The two pieces of the paper were joined together just like a jigsaw. A solid-contact $\mathrm{Cl}^{-}$-selective electrode and a reference electrode were gently pressed onto the detection zone to create a direct contact between the electrodes and the solution absorbed in the paper. Utilizing the possibility to form stable complexes between $\mathrm{Fe}^{3+}$ and salicylate, the proposed platform enables the separation of salicylate and detection of chloride. This system offers a convenient platform for both sampling and separation of ions, in which sample pretreatment procedures can be simplified or avoided.
\end{abstract}

(c) 2016 Elsevier B.V. All rights reserved.

\section{Introduction}

Potentiometry based on polymeric membrane ion-selective electrodes (ISEs) has long been regarded as a promising tool for the determination of ion activities [1,2]. With the introduction of better molecular receptors, new membrane materials and novel sensing concepts, the performance of ISEs has been dramatically improved during the past two decades [3,4]. A number of ISEs are available with high enough selectivity towards the target analyte to be applied in clinical-, process- and environmental analysis. However, the use of ISEs is sometimes restricted by interferences from the sample matrix $[5,6]$.

To reduce the sample matrix effects on potentiometric ion sensing, separation and pre-concentration of the target analyte has been adopted, e.g. by coupling the potentiometric detection with separation using liquid chromatography [7]. This approach, however, requires sophisticated and relatively expensive instrumentation. Furthermore, pre-concentration and matrix elimination procedures based on electrochemical accumulation, magnetic sep-

\footnotetext{
* Corresponding author.

E-mail address: johan.bobacka@abo.fi (J. Bobacka).
}

aration or paper-based filtration are alternative choices to enhance the performance of ISEs for potentiometric measurements [8-11]. In all these methods, medium exchange is an essential step for subsequent potentiometric detection, which has the drawbacks of tedious measurement protocols. Thus, there is a clear need to develop a convenient separation platform when using ISEs as a detector.

Paper with its unique features such as low cost, feasible mass production, and pumpless liquid transport operation has been adopted as an attractive analytical and detection platform [12,13]. To date, microfluidic paper-based analytical devices ( $\mu$ PADs) with various readout principles and chemical functions have been designed [14-20]. Among those paper-based sensing platforms, $\mu$ PADs coupled with potentiometric detection offer a selective and sensitive platform for ion sensing. Recently, our group provided a potentiometric ion sensing platform utilizing paper- and textilebased sampling [21-23]. Bühlmann, Whitesides et al. and our group designed $\mu$ PADs into which a solid-state ISE and an all-solid-state reference electrode can be integrated for ion sensing and biosensing [24-27]. Furthermore, in situations where the ISE itself is not selective enough, paper-based pre-separation of the analyte from interfering ions can be a valuable option. 


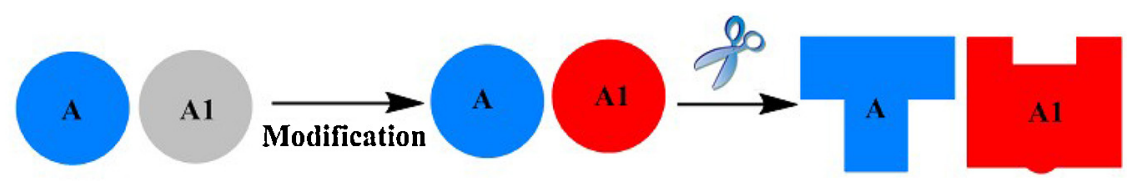

Filter paper
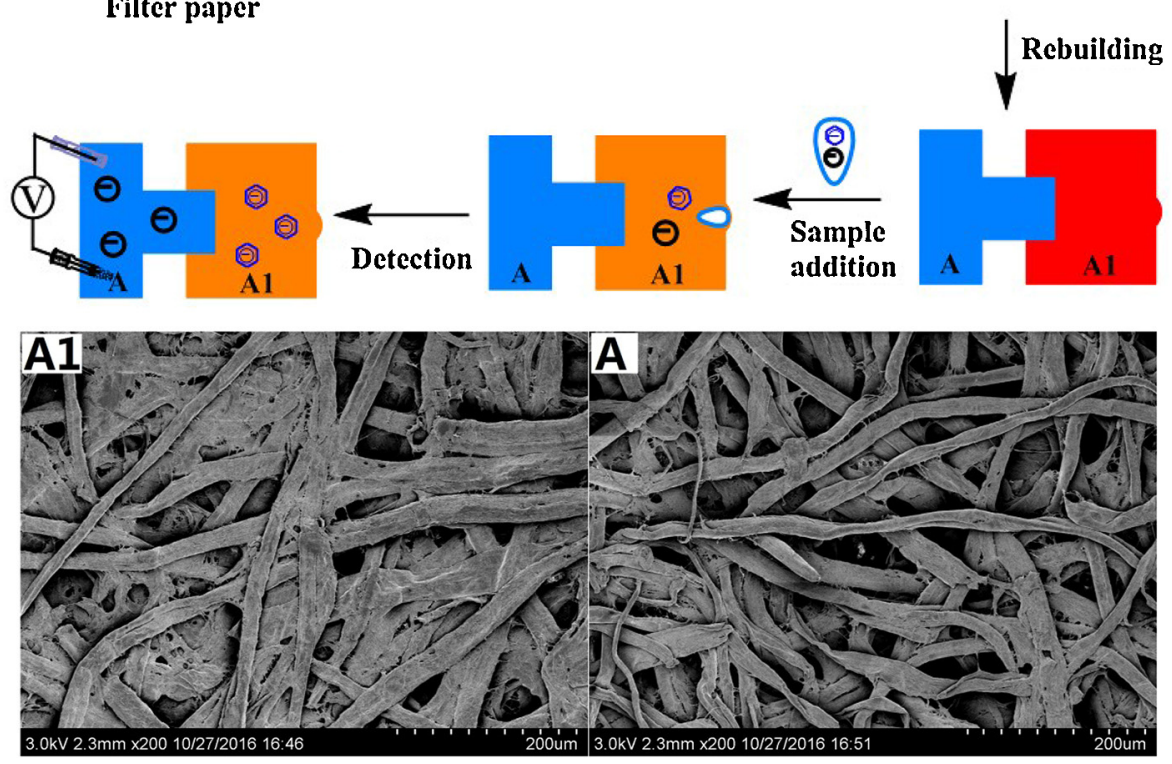

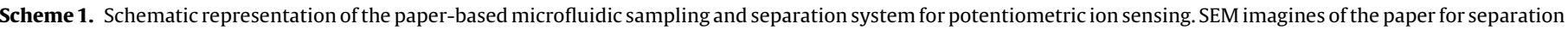
zone (A1) and detection zone (A) are also shown.

Herein, a paper-based microfluidic sampling and separation system was exploited for potentiometric ion sensing (Scheme 1). The device was composed of two pieces of paper with different shapes and pore sizes. A "T" shaped filter paper with a pore size of $12-25 \mu \mathrm{m}$ ("A" in Scheme 1) served as the detection zone, while a filter paper with a pore size of $2.0 \mu \mathrm{m}$ ("A1" in Scheme 1) was modified with a complexing agent and served as the separation zone. Interfering ions present in the sample solution bind to the complexing agent to form a complex, which retards the migration of the interfering ions to the detection zone. On the contrary, the target ions were readily wicked into the detection zone, where potentiometric measurements took place.

Chloride $\left(\mathrm{Cl}^{-}\right)$is an important analyte in clinical analysis, while its detection with ISEs is challenging when salicylate (the major metabolite of aspirin) is present [28]. The therapeutic concentration of salicylate in plasma is up to 1-2 mM [29]. Furthermore, according to the Hofmeister series, the presence of high concentrations of salicylates can strongly interfere with the potentiometric detection of $\mathrm{Cl}^{-}$[30]. As a proof of concept, the potentiometric detection of $\mathrm{Cl}^{-}$in the presence of a high concentration of salicylate was therefore selected as a model system to develop and evaluate our paper-based sampling and separation system.

\section{Experimental}

\subsection{Materials}

Azulene (99\%), $\mathrm{Fe}_{2}\left(\mathrm{SO}_{4}\right)_{3}$, and acetonitrile ( $\mathrm{ACN}, 99.5 \%$, anhydrous) were obtained from Aldrich and used without additional purification. Tetrabutylammonium hexafluorophosphate TBAPF $_{6}$, 99\%), 2-nitrophenyl octyl ether (o-NPOE), tridodecylmethylammonium chloride (TDMACl), high molecular weight poly(vinyl chloride) (PVC), and tetrahydrofuran (THF) were purchased from Fluka and used as received. Sodium chloride and sodium salicylate were obtained from Merck. Aqueous solutions were prepared with freshly deionized water (resistivity $=18.2 \mathrm{M} \Omega \mathrm{cm}$ ) obtained with the ELGA purelab ultra water system (High Wycombe, United Kingdom). Calibration serum solutions with different ion composition were provided by Thermo Scientific. Black ribbon ashless filter paper (Whatman Grade 589/1, pore size $=12-25 \mu \mathrm{m}$ ) and Blue ribbon ashless filter paper (Whatman Grade 589/3, pore size $=2.0 \mu \mathrm{m}$ ) were obtained from Schleicher \& Schuell GmbH (Dassel, Germany).

\subsection{Electrode preparation}

Glassy carbon (GC) disk electrodes with a diameter of $3.0 \mathrm{~mm}$ (inserted in a PVC housing with outer diameter $=1 \mathrm{~cm}$ ) were polished and used for the construction of solid-contact ISEs for $\mathrm{Cl}^{-}$. In the three-electrode cell, a coiled Pt wire and an $\mathrm{Ag} / \mathrm{AgCl}$ wire served as the counter and the reference electrode (calibrated versus ferrocene/ferrocenium, $\mathrm{E}_{\mathrm{redox}}=0.36 \mathrm{~V}$ ), respectively. All polymerizations were done in $\mathrm{ACN}$ solutions containing $0.01 \mathrm{M}$ azulene and $0.1 \mathrm{M} \mathrm{TBAPF}_{6}$ by cycling the potential between $-0.6 \mathrm{~V}$ and $1.2 \mathrm{~V}$ with the scan rate of $50 \mathrm{mV} \mathrm{s}^{-1}$ (Autolab PGSTAT 30 potentiostat equipped with the GPES software) [31,32]. The number of polymerization cycles was 10 . All solutions used for polymerization of the PAz films $(3.0 \mathrm{~mL})$ were purged with nitrogen for $5 \mathrm{~min}$ before the experiments and the $\mathrm{TBAPF}_{6}$ salt was dried under vacuum at $80{ }^{\circ} \mathrm{C}$ for $30 \mathrm{~min}$ prior to use. The ion-selective membranes contained 34\% PVC, 51\% o-NPOE and 15\% TDMACl. $40 \mu \mathrm{L}$ membrane cocktail was applied per electrode by drop casting on the glassy carbon/PAz electrodes. All the electrodes were conditioned in $10^{-3} \mathrm{M}$ $\mathrm{NaCl}$ overnight. When not in use, the electrodes were conditioned in $10^{-3} \mathrm{M} \mathrm{NaCl}$.

\subsection{Design of the paper-based analytical devices}

The device comprised of a separation zone $(15 \mathrm{~mm} \times 15 \mathrm{~mm})$ with a pore size of $2.0 \mu \mathrm{m}$ which contained $\mathrm{Fe}^{3+}$ and a detection zone $(20 \mathrm{~mm} \times 10 \mathrm{~mm})$ equipped with a microfluidic channel $(10 \mathrm{~mm} \times 10 \mathrm{~mm})$ in the form of a "T" shaped filter paper with a pore size of $12-25 \mu \mathrm{m}$. Before the measurements the two pieces of 
the paper (separation and detection zones) were joined together just like a jigsaw. The bottom side of the connection area was covered with clear packing tape to ensure a close connection between the two pieces of paper, allowing the liquid (sample) to migrate from one piece of paper to the other via capillary forces (wicking). The structural feature of the paper was characterized by scanning electron microscopy (SEM, JSM5600 LV, operating at 5.0 KV).

\subsection{Functionalization of filter paper}

One piece of Whatman filter paper with a diameter $110 \mathrm{~mm}$ and pore size of $2.0 \mu \mathrm{m}$ (blue ribbon) was dipped into $0.01 \mathrm{M} \mathrm{Fe}_{2}\left(\mathrm{SO}_{4}\right)_{3}$ solution for $1 \mathrm{~h}$ in order for iron(III) to absorb into the paper substrate. Then the $\mathrm{Fe}^{3+}$-impregnated filter papers were washed with distilled water for 3 times to remove the excess (weakly adsorbed) iron(III), which was followed by drying the paper substrate in air at room temperature.

\subsection{Potentiometric measurements with ISEs}

Potentiometric measurements were performed using an EMF16 Interface (Lawson Labs Inc., USA). The activity coefficients were calculated by using the extended Debye-Hückel equation [33]. Measurements for selectivity coefficients were done using the electrode conditioned in $10^{-3} \mathrm{M} \mathrm{NaCl}$. The selectivity of the $\mathrm{GC} / \mathrm{PAz} / \mathrm{PVC}-\mathrm{TDMACl}\left(\mathrm{Cl}^{-}\right.$-ISE) electrode was determined using the separate solution method to evaluate the influence of the interfering ions [34]. A single junction $\mathrm{Ag} / \mathrm{AgCl} / 3 \mathrm{M} \mathrm{KCl}$ reference electrode (6.0733.100, Herisau, Switzerland) was used here because it has its porous plug at the very end of the electrode, thereby giving a proper contact (liquid junction) to the sample/paper substrate when the electrode was gently pressed against the paper. The paper device was positioned horizontally on the support surface (Teflon plate), while the $\mathrm{Cl}^{-}$-ISE and the reference electrode were positioned vertically to the detection zone $(20 \mathrm{~mm} \times 10 \mathrm{~mm})$ of the paper device. The $\mathrm{Cl}^{-}$-ISE had an outer diameter (=membrane diameter) of $1 \mathrm{~cm}$. The electrodes were fixed in place by using a standard laboratory stand so that the distance between the working areas of the two electrodes was kept constant (ca $9 \mathrm{~mm}$ apart from each other). The physical separation of the two electrodes was applied to deal with the possible contamination (within 90 s measurement time) of the paper/sample by the $3 \mathrm{M} \mathrm{KCl}$ solution leaching out from the liquid junction of the reference electrode. A new piece of paper device was used for each standard and sample solution, thereby minimizing any contamination from chloride. The sample solution $(150 \mu \mathrm{L})$ was added on top of the separation part ("A1" in Scheme 1) and then it wicked through the separation zone into the detection zone ("A" in Scheme 1). After the detection zone was completely wet (ca $60 \mathrm{~s}$ after sample addition), the indicator and the reference electrode were gently pressed onto the detection zone for potentiometric measurements. The time required for the manual fixation of the electrodes was ca $30 \mathrm{~s}$. Thereafter, the EMF response was recorded for $90 \mathrm{~s}$. The time ( $90 \mathrm{~s}$ ) was a compromise between allowing sufficient time for stabilization of the potential on one hand and minimizing possible effects of sample evaporation on the other hand. After each measurement, the electrodes were rinsed with deionized water.

\section{6. $\mathrm{Fe}^{3+}$ determination by $\mathrm{UV}-$ Vis spectroscopy}

$\mathrm{Fe}^{3+}$ was determined according to a previous report with some modification [35]. Briefly, a functionalized filter paper with a diameter of $69 \mathrm{~mm}$ was immersed into $4.5 \mathrm{~mL} 0.5 \mathrm{M} \mathrm{HCl}$ and incubated overnight at room temperature. $100 \mu \mathrm{L}$ acidified sample aliquots were reacted with ferrozine reagent $(0.1 \mathrm{wt}-\%$ ferrozinein, $200 \mathrm{mmol} \mathrm{L}^{-1}$ HEPES buffer, $\mathrm{pH} 7.0$ ), and the ferrozine-Fe(II) com-

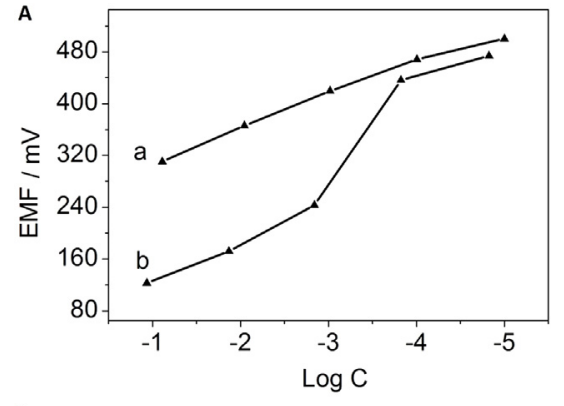

B

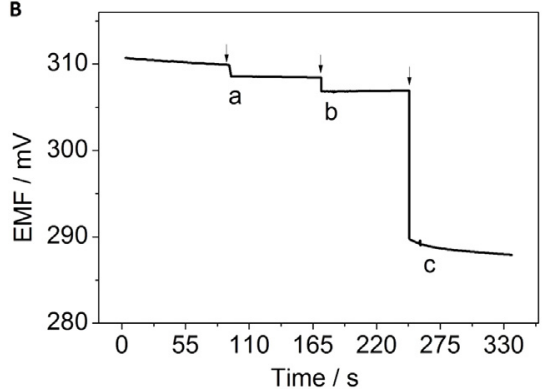

Fig. 1. (A) $E M F$ responses (beaker-based measurements) of the ISEs toward (a) $\mathrm{NaCl}$ and (b) salicylate. (B) $E M F$ responses of the ISEs to $0.1 \mathrm{M} \mathrm{NaCl}$ in the presence of (a) $1.5 \times 10^{-5} \mathrm{M}$, (b) $1.5 \times 10^{-4} \mathrm{M}$ and (c) $1.5 \times 10^{-3} \mathrm{M}$ salicylate.

plex was quantified at $562 \mathrm{~nm}$ by UV-vis spectrophotometry (Thermo Scientific, Genesys 10 s UV-vis, USA).

\section{Results and discussion}

\subsection{Solid-contact ISEs for $\mathrm{Cl}^{-}$}

As a proof-of-concept experiment, solid-contact ISEs for $\mathrm{Cl}^{-}$ were prepared by using electrosynthesized polyazulene (PAz) as the solid-contact $[31,32]$, coated with a plasticized PVC-based membrane containing TDMACl as ion exchanger for $\mathrm{Cl}^{-}[36]$. The resulting electrodes are denoted as GC/PAz/PVC-TDMACl. Beakerbased measurements were carried out first. Fig. 1A (curve a) shows that the electrode exhibited a linear response $\left(r^{2}=0.997\right)$ over the $\mathrm{Cl}^{-}$activities from $1.0^{-1}$ to $1.0^{-4} \mathrm{M}$ with a slope of $54.7 \mathrm{mV} / \mathrm{pCl}^{-}$and a detection limit of approximately $10^{-5} \mathrm{M}$ in pure chloride $(\mathrm{NaCl})$ standard solutions. A super-Nernstian response to salicylate was observed (Fig. 1A, curve b) when the electrode was initially conditioned in $10^{-3} \mathrm{M} \mathrm{NaCl}$, which may due to the non-equilibrium response toward the lipophilic salicylate ion. The selectivity coefficient (in logarithmic scale) for chloride over salicylate and $\mathrm{SO}_{4}{ }^{2-}$ were determined to be $+3.4 \pm 0.04$ and $-2.5 \pm 0.05$, respectively, which is in good agreement with those reported earlier [30]. Such a low selectivity for chloride over salicylate is demonstrated in Fig. 1B that shows the response of the $\mathrm{Cl}^{-}$ISE to the added salicylate. Even small additions of salicylate to the chloride ion solution change the $E M F$ of the electrode (a, b), which is followed by the dramatic drop of EMF after addition of $1.5 \times 10^{-3} \mathrm{M}$ salicylate (c). Therefore, the presence of lipophilic salicylate in the solution would make the direct determination of $\mathrm{Cl}^{-}$virtually impossible in clinical samples with this particular $\mathrm{Cl}^{-}$ISE.

Indeed, the presence of high concentration of salicylate in human serum caused an elevation of the measured chloride level [37]. Although the introduction of new ionophores, epoxy resin-based anion-responsive polymers and asymmetric two-layer membrane structures have shown remarkable reduction of the interferences from salicylate and made the sensing membrane feasible for practical applications and even available in commercial blood analyzers [38-41], cost-effective and simple-to-use methods 


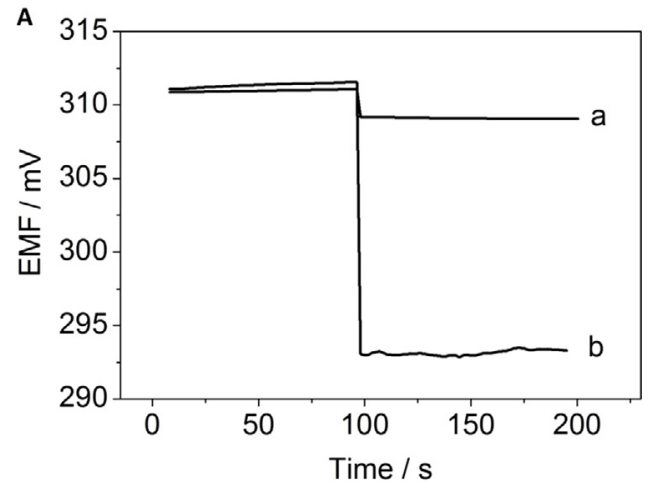

B

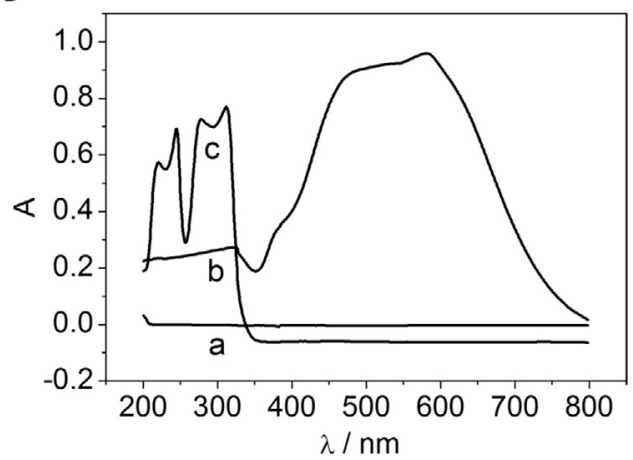

Fig. 2. (A) $E M F$ responses (beaker-based measurements) of the ISEs toward $0.1 \mathrm{M}$ $\mathrm{NaCl}$ containing $1.5 \mathrm{mM}$ salicylate in the presence (a) and absence (b) of $\mathrm{Fe}^{3+}$. (B) UV-vis spectra of $0.1 \mathrm{M} \mathrm{NaCl}(\mathrm{a}), 0.1 \mathrm{M} \mathrm{NaCl}$ containing $1.5 \mathrm{mM}$ salicylate in the presence (b) and absence (c) of $1.0 \mathrm{mM} \mathrm{Fe}^{3+}$.

for determination of chloride ions in the presence of interfering ions are still required.

\subsection{Interactions between $\mathrm{Fe}^{3+}$ and salicylate}

It has been found that salicylate can bind $\mathrm{Fe}^{3+}$ into a purpleviolet complex that can be monitored spectrophotometrically [42]. Beaker-based measurements were first carried out to investigate the interactions between $\mathrm{Fe}^{3+}$ and salicylate. As can be seen from Fig. 2A, a large potential decrease of $\mathrm{Cl}^{-}$ISE can be observed in the presence of $1.5 \mathrm{mM}$ salicylate compared to the potential of the electrode for the pure $0.1 \mathrm{M} \mathrm{NaCl}$ solution. On the contrary, salicylate causes only a slight potential difference in the presence of $\mathrm{Fe}^{3+}$, which is due to the formation of a complex of salicylate and $\mathrm{Fe}$ (III) ions. Since the binding constant between $\mathrm{Fe}^{3+}$ and salicylate is ca $2.73 \times 10^{17}$, salicylate in the complex cannot be extracted into the membrane to produce a potential response [43]. Furthermore, the absorption spectrum of salicylate is suppressed in the presence of $\mathrm{Fe}^{3+}$, assuring complexation of salicylate by iron(III). Instead, a new broad absorption band with a maximum around $580 \mathrm{~nm}$ arises owing to the presence of the Fe(III)-salicylate complex (Fig. 2B) [28]. Although a high concentration of stable complexes may lead to a slight potential change in beaker-based measurements (Fig. 2A), $\mathrm{Fe}^{3+}$ can be used as a shielding reagent and adsorbed on the filter paper for determination of chloride ions in the presence of salicylate.

\subsection{Paper-based microfluidic sampling and separation platform}

Previous research has shown that the properties of the filter paper determine the wicking speed and could affect the contact time between the sample and the reagents [44]. Thus, the differences in properties for each paper may be useful in microfluidic sampling and separation of analytes. In this work, two paper substrates with different pore size and wicking speed were used. Whatman grade 1 filter paper (pore size $=2.0 \mu \mathrm{m}$ ) with a relatively low wicking speed could prolong the contact time between the sample and the reagents and was selected for the separation zone to facilitate the separation of the interfering ions from the sample. Conversely, a filter paper with a pore size of $12-25 \mu \mathrm{m}$ was used for the detection zone, because it provides a much higher flow rate, which allows rapid measurements and reduces the effect of water evaporation (Scheme 1). The SEM images in Scheme 1 show the differences in pore size and fiber thickness between the filter papers used for the separation zone (A1) and the detection zone (A).

Utilizing the possibility to form stable complexes between $\mathrm{Fe}(\mathrm{III})$ and salicylate, we describe herein a paper-based microfluidic platform consisting of a separation unit (paper containing $\mathrm{Fe}^{3+}$ ) for the separation of salicylate and detection of chloride (Fig. 3A). The functionalization of the separation zone by $\mathrm{Fe}^{3+}$ was done utilizing paper, where cellulose and $\mathrm{Fe}^{3+}$ interact strongly with each other through electrostatic adsorption and hydrogen bonding [45]. To confirm functionalization, the absorbed $\mathrm{Fe}^{3+}$ was extracted and quantified by UV-vis spectroscopy resulting in $0.85 \mu \mathrm{mol} \mathrm{Fe}{ }^{3+}$ absorbed in a filter paper of size $15 \times 15 \mathrm{~mm}^{2}$, which is the size of the separation zone used ("A1" in Scheme 1). In this work, $150 \mu \mathrm{L}$ of sample solution was added on the separation zone, and if all of the absorbed $\mathrm{Fe}^{3+}$ dissolved in this volume, then the concentration of $\mathrm{Fe}^{3+}$ was $5.6 \pm 0.9 \mathrm{mM}(\mathrm{n}=3)$. Since the predominant stoichiometry of the Fe(III)-salicylate coordination complex formed is $1: 1$, the concentration of $\mathrm{Fe}(\mathrm{III})$ on the paper substrate was enough to eliminate salicylate interferences under the experimental conditions used here [43].

Interestingly, the operation and effectiveness of the device can be observed by the naked eye. As the solution passed through the separation zone, salicylate in the solution was largely retained by $\mathrm{Fe}^{3+}$ ions. The color of the separation zone thus changed from light

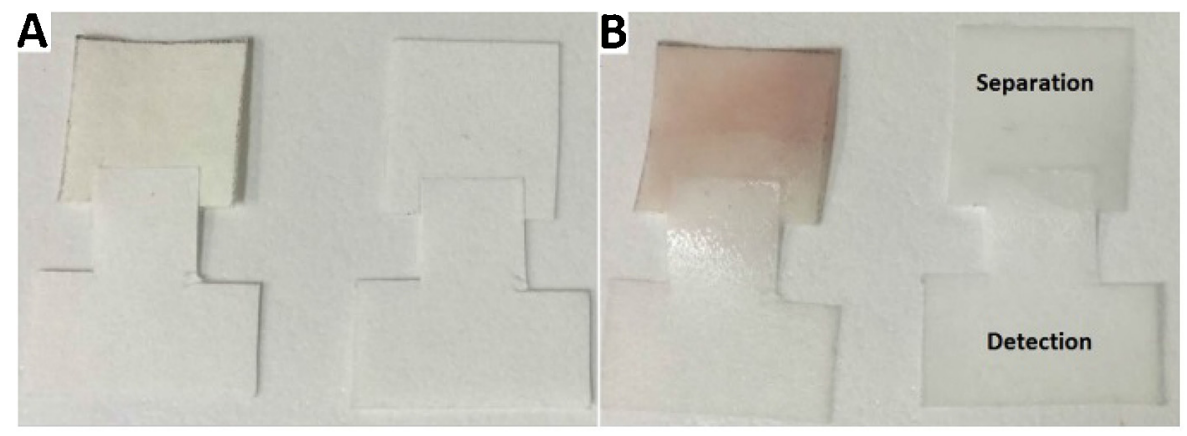

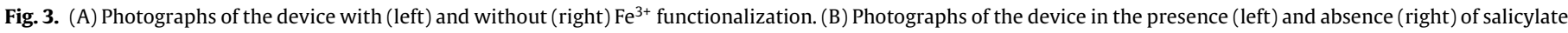
in the sample solution. 


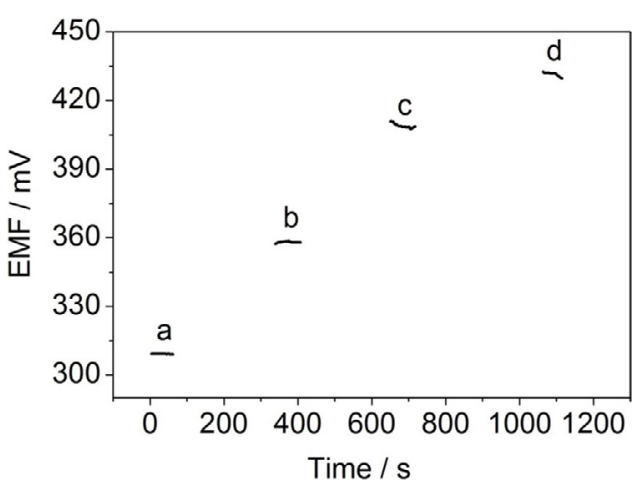

Fig. 4. Potentiometric response of the solid-contact $\mathrm{Cl}^{-}$-ISE utilizing the proposed paper-based analytical device for sampling of standard solutions of $10^{-1}$ (a), $10^{-2}$ (b), $10^{-3}$ (c) and $10^{-4} \mathrm{M} \mathrm{NaCl}(\mathrm{d})$.

yellow (Fig. 3A left) to purple-violet (Fig. 3B left) due to the formation of the Fe(III)-salicylate complex.

Due to the small volume of sample solution $(150 \mu \mathrm{L})$ and its evaporation, the EMF responses were recorded for only 90 s. EMF measurements utilizing the paper-based device were carried out for determination of standard solutions and the results are shown in Fig. 4. A linear response can be observed for the $\mathrm{Cl}^{-}$-ISEs when the measurement was run in decreasing $\mathrm{Cl}^{-}$activity from $10^{-1}$ to $10^{-3}$. A slope of $52.4 \pm 0.7$ was obtained, which is slightly lower than that observed in beaker-based measurement (Fig. 1A). For the proposed $\mathrm{Cl}^{-}$-ISE the lower detection limit is higher using paper-based sampling than in beaker-based measurements. This phenomenon has also been observed in textile-based sampling for $\mathrm{Cl}^{-}$[23].

To evaluate the measurement time on the potential response, the potentiometric measurement was run for more than $600 \mathrm{~s}$ in each solution. As shown in Fig. 5, the potential responses of the $\mathrm{Cl}^{-}$-ISE are similar for both paper- and beaker-based measurements. Moreover, the paper containing Fe(III) behaved similarly to the paper substrate without $\mathrm{Fe}(\mathrm{III})$ when detecting $\mathrm{Cl}^{-}$in absence of salicylate. There was a clear potential drift in paper-based measurements and the potential drift was more obvious at low concentrations of $\mathrm{Cl}^{-}$(as can be seen from Fig. 4). During the first $90 \mathrm{~s}$, the drift was in the range $0.01-0.03 \mathrm{mV} \mathrm{s}^{-1}$ for the detection of low concentrations of $\mathrm{Cl}^{-}$. Since the drift was most obvious for low chloride concentrations, and slightly higher for paper-based sampling than beaker-measurements, it can tentatively be related to chloride-interference from the reference electrode and/or evaporation. The overall potential drift in absence (Fig. 5 curve b) and presence of $\mathrm{Fe}^{3+}$ (Fig. 5, curve c) are similar for the paper-based sampling, indicating that the presence of $\mathrm{Fe}^{3+}$ does not signifi-

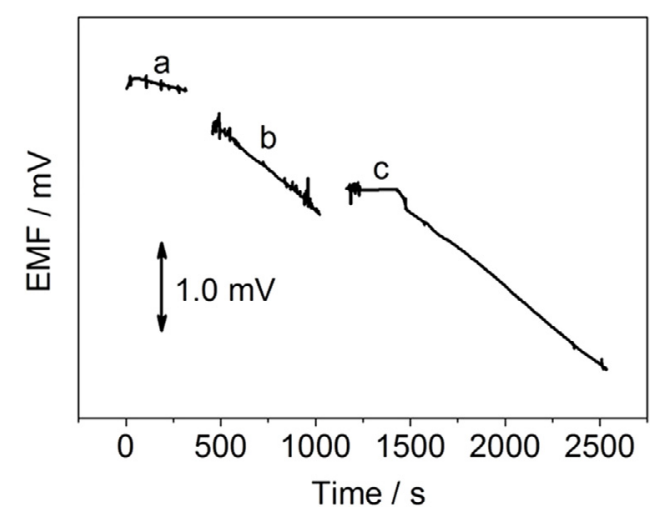

Fig. 5. Potentiometric response of the solid-contact $\mathrm{Cl}^{-}$-ISE for $0.1 \mathrm{M} \mathrm{NaCl}$ in beaker(a) and paper-based measurements without (b) and with (c) modification by $\mathrm{Fe}^{3+}$.
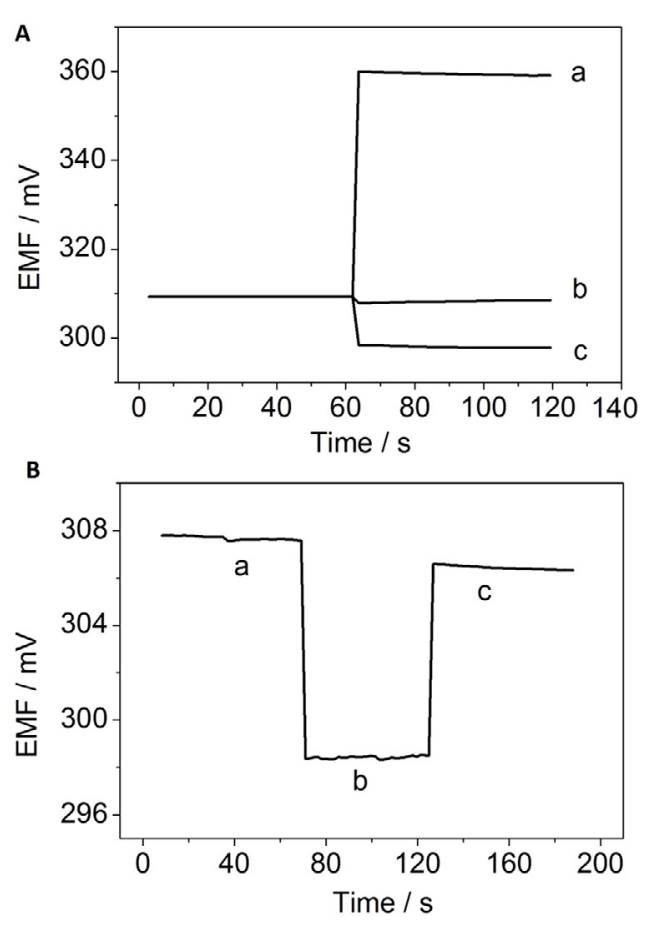

Fig. 6. (A) $E M F$ responses of the device with (a,b) and without (c) $\mathrm{Fe}^{3+}$ functionalization toward $0.01 \mathrm{M} \mathrm{NaCl}$ (a) and $0.1 \mathrm{M} \mathrm{NaCl}$ containing $1.5 \mathrm{mM}$ salicylate $(b, c)(B)$ $E M F$ responses of the device with $(\mathrm{a}, \mathrm{c})$ and without $(\mathrm{b}) \mathrm{Fe}^{3+}$ functionalization toward serum alone (a) and serum containing $1.5 \mathrm{mM}$ salicylate (b,c).

cantly influence the potential drift. A slight potential drift due to the solid-contact ISE cannot be excluded [23].

\subsection{Paper-based microfluidic sampling and separation of salicylate}

To demonstrate the feasibility of the device for potentiometric ion sensing, $0.1 \mathrm{M} \mathrm{NaCl}$ sample solution in the absence and presence of $1.5 \mathrm{mM}$ salicylate were measured (Fig. 6A). For the paper device without $\mathrm{Fe}(\mathrm{III})$, the recorded potential showed a large decrease in the presence of $1.5 \mathrm{mM}$ salicylate (Fig. $6 \mathrm{~A}$, curve c). However, only a small potential change was observed for the paper device containing Fe(III) (Fig. 6A, curve b). These results indicate that the salicylate is indeed capable of being separated by complexation with Fe(III). Moreover, the separation process may be facilitated also by nonspecific adsorption of the lipophilic ions on the filter paper.

The analytical feasibility of this paper-based device was evaluated also in serum samples. The matrix effect of human serum was first evaluated via potentiometric sensing. As illustrated in Fig. 6B, spiking serum with $1.5 \mathrm{mM}$ salicylate resulted in about $10 \mathrm{mV}$ potential decrease for the paper device without $\mathrm{Fe}^{3+}$. On the contrary, the paper device containing $\mathrm{Fe}^{3+}$ showed a potential change of only ca. $1 \mathrm{mV}$, which could even be attributed to the potential drift of the electrode in the complex sample matrix. The result is encouraging, but extensive optimization of the paper-based analytical procedure would still be required in order to achieve the extremely high accuracy, repeatability and reproducibility that would be required for clinical analysis. However, the results presented in this work demonstrate the feasibility of paper-based microfluidic sampling and separation of analytes combined with potentiometric sensing. 


\section{Conclusions}

In conclusion, a low-cost, simple, disposable paper-based microfluidic sampling and separation platform for potentiometric sensing was demonstrated. The advantage of this system is in the use of paper for both sampling and separation of ions. Thus, any complex pretreatment procedures can be simplified or avoided. It should be noted that many pieces of separation zones with different shielding reagents can in principle be designed and connected together just like a jigsaw. In that way, different types of interferences can be eliminated to facilitate the subsequent potentiometric detection. We also anticipate that this strategy potentially broadens the range of analytes that can be measured by potentiometric ion sensors.

\section{Acknowledgements}

J.W. Ding gratefully acknowledges the Johan Gadolin Scholarship provided by the Johan Gadolin Process Chemistry Centre at Åbo Akademi University and the financial support of the National Natural Science Foundation of China (21575158). We also acknowledge Hongxia Zhang from Yantai Institute of Coastal Zone Research who provided reagents for the $\mathrm{Fe}^{3+}$ measurements. This research is part of the activities of the Johan Gadolin Process Chemistry Centre, a centre of excellence at Åbo Akademi University.

\section{References}

[1] E. Bakker, E. Pretsch, Modern potentiometry, Angew. Chem. Int. Ed. 46 (2007) 5660-5668.

[2] J. Bobacka, A. Ivaska, A. Lewenstam, Potentiometric ion sensors, Chem. Rev. 108 (2008) 329-351.

[3] E. Bakker, Electroanalysis with membrane electrodes and liquid-liquid interfaces, Anal. Chem. 88 (2016) 395-413

[4] T.J. Yin, W. Qin, Applications of nanomaterials in potentiometric sensors, Trends Anal. Chem. 51 (2013) 79-86.

[5] P. Bühlmann, E. Pretsch, E. Bakker, Carrier-based ion-selective electrodes and bulk optodes. 1. general characteristics, Chem. Rev. 97 (1997) 3083-3132.

[6] W. Qin, R.N. Liang, X.L. Fu, Q.W. Wang, T.J. Yin, W.J. Song, Trace-level potentiometric detection in the presence of a high electrolyte backgroud, Anal. Chem. 84 (2012) 10509-10513.

[7] X.W. Wang, A.S. Balijepalli, M.E. Meyerhoff, Polyion-sensitive polymeric membrane-based pulstrode as a potentiometric detector in liquid chromatography, Electroanalysis 27 (2015) 1823-1828.

[8] K.Y. Chumbimuni-Torres, P. Calvo-Marzal, J. Wang, E. Bakker, Electrochemical sample matrix elimination for trace-level potentiometric detection with polymeric membrane ion-selective electrodes, Anal. Chem. 80 (2008) 6114-6118.

[9] G.A. Zelada-Guilleín, S.V. Bhosale, J. Riu, F.X. Rius, Real-time potentiometric detection of bacteria in complex samples, Anal. Chem. 82 (2010) 9254-9260.

[10] J.W. Ding, J.H. Lei, X. Ma, J. Gong, W. Qin, Potentiometric aptasensing of Listeria monocytogenes using protamine as an indicator, Anal. Chem. 86 (2014) 9412-9416.

[11] J.W. Ding, Y. Gu, F. Li, H.X. Zhang, W. Qin, DNA nanostructure-based magnetic beads for potentiometric aptasensing, Anal. Chem. 87 (2015) 6465-6469.

[12] S.K. Mahadeva, K. Walus, B. Stoeber, Paper as a platform for sensing applications and other devices: a review, ACS Appl. Mater. Interfaces 7 (2015) 8345-8362.

[13] D.M. Cate, J.A. Adkins, J. Mettakoonpitak, C.S. Henry, Recent developments in paper-based microfluidic devices, Anal. Chem. 87 (2015) 19-41.

[14] G.M. Whitesides, The origins and the future of microfluidics, Nature 442 (2006) 368-373

[15] A.W. Martinez, S.T. Phillips, G.M. Whitesides, E. Carrilho, Diagnostics for the developing world: microfluidic paper-based analytical devices, Anal. Chem. $82(2010) 3-10$

[16] W. Dungchai, O. Chailapakul, C.S. Henry, Electrochemical detection for paper-based microfluidics, Anal. Chem. 81 (2009) 5821-5826.

[17] H. Liu, R.M. Crooks, Three-dimensional paper microfluidic devices assembled using the principles of origami, J. Am. Chem. Soc. 133 (2011) 17564-17566.

[18] X.W. Wang, Y. Qin, M.E. Meyerhoff, Paper-based plasticizer-free sodium ion-selective sensor with camera phone as a detector, Chem. Commun. 51 (2015) 15176-15179.

[19] B. Weigl, G. Domingo, P. LaBarre, J, Gerlach Towards non-and minimally instrumented, microfluidics-based diagnostic devices, Lab Chip 8 (2008) 1999-2014.

[20] M. Cuartero, G.A. Crespo, E. Bakker, Paper-based thin-layer coulometric sensor for halide determination, Anal. Chem. 87 (2015) 1981-1990.
[21] J. Cui, G. Lisak, S. Strzalkowska, J. Bobacka, Potentiometric sensing utilizing paper-based microfluidic sampling, Analyst 139 (2014) 2133-2136.

[22] G. Lisak, J. Cui, J. Bobacka, Paper-based microfluidic sampling for potentiometric determination of ions, Sens. Actuators B 24 (2015) 933-939.

[23] G. Lisak, T. Arnebrant, T. Ruzgas, J. Bobacka, Textile-based sampling for potentiometric determination of ions, Anal. Chim. Acta 877 (2015) 71-79.

[24] W.J. Lan, X.U. Zou, M.M. Hamedi, J.B. Hu, C. Parolo, E.J. Maxwell, P. Buhlmann, G.M. Whitesides, Paper-based potentiometric ion sensing, Anal. Chem. 86 (2014) 9548-9553.

[25] J.B. Hu, K.T. Ho, X.U. Zou, W.H. Smyrl, A. Stein, P. Bühlmann, All-solid-state reference electrodes based on colloid-imprinted mesoporous carbon and their application in disposable paper-based potentiometric sensing devices, Anal. Chem. 87 (2015) 2981-2987.

[26] J.B. Hu, A. Stein, P. Bühlmann, A disposable planar paper-based potentiometric ion-sensing platform, Angew. Chem. Int. Ed. 55 (2016) 7544-7547.

[27] J.W. Ding, B.W. Li, L.X. Chen, W. Qin, A three-dimensional origami paper-based device for potentiometric biosensing, Angew. Chem. Int. Ed. 55 (2016) 13033-13037.

[28] S.S. Mitić, G. Miletić, I.D. Rašić, A.N. Pavlović, Kinetic quantification of sodium salicylate in human serum and wine, J. Anal. Chem. 66 (2011) 94-101.

[29] R.M. Harris, R.J. Hawker, M.J.S. Langman, S. Singh, R.H. Waring, Inhibition of phenolsulphotransferase by salicylic acid: a possible mechanism by which aspirin may reduce carcinogenesis, Gut 42 (1998) 272-275.

[30] P. Sjoberg-Eerola, J. Bobacka, A. Lewenstam, A. Ivaska, All-solid-state chloride sensors based on electronically conducting, semiconducting and insulating polymer membranes, Sens. Actuators B 127 (2007) 545-553.

[31] N. He, R.E. Gyurcsányi, T. Lindfors, Electropolymerized hydrophobic polyazulene as solid-contact in potassium-selective electrodes, Analyst 141 (2016) 2990-2997.

[32] N. He, L. Höfler, R.M. Latonen, T. Lindfors, Influence of hydrophobization of the polyazulene ion-to-electron transducer on the potential stability of calcium-selective solid-contact electrodes, Sens. Actuators B 207 (2015) 918-925.

[33] S. Kamata, A. Bhale, Y. Fukunaga, H. Murata, Copper(II)-selective electrode using thiuram disulfide neutral carriers, Anal. Chem. 60 (1988) 2464-2467.

[34] E. Bakker, Determination of improved selectivity coefficients of polymer membrane ion-selective electrodes by conditioning with a discriminated ion, J. Electrochem. Soc. 143 (1996) L83-L85.

[35] S.L. Zhen, H.X. Zhang Y. Li, H. Zhang O.M. Wang J. Zhang F.F. Liu, Co-occurrence of Methanosarcina mazei and Geobacteraceae in an iron (III)-reducing enrichment culture, Front. Microbiol. 6 (2015) 1-8.

[36] P. Sjöberg-Eerol, J. Nylund, J. Bobacka, A. Lewenstam, A. Ivaska, Soluble semiconducting poly(3-octylthiophene) as a solid-contact material in all-solid-state chloride sensors, Sens. Actuators B 134 (2008) 878-886.

[37] A.R. Craig, M.P. Reidy, C.R. Wang, Chloride ion selective membrane electrode having improved stability and selectivity, 2000, U.S. Pat. No. 6, 015,480.

[38] I.J. Yoon, J.H. Shin, I.R. Paeng, H. Nam, G.S. Cha, K.J. Paeng, Potentiometric behavior of metalloporphyrin-based ion-selective electrodes: use of silicone rubber matrix for serum chloride analysis, Anal. Chim. Acta 367 (1998) $175-181$.

[39] K.L. Gemene, M.E. Meyerhoff, Selectivity enhancement for chloride ion by In(III)-porphyrin-based polymeric membrane electrode operated in pulsed chronopotentiometric mode, Electroanalysis 24 (2012) 643-648.

[40] M.J. Cha, J.H. Shin, B.K. Oh, C.Y. Kim, G.S. Cha, D.S. Shin, B. Kim, Asymmetric cellulose acetate membrane-based carbonate-and chloride-selective electrodes, Anal. Chim. Acta 315 (1995) 311-319.

[41] J.H. Shin, H.L. Lee, S.H. Cho, J. Ha, H. Nam, G.S. Cha, Characterization of epoxy resin-based anion-responsive polymers: applicability to chloride sensing in physiological samples, Anal. Chem. 76 (2004) 4217-4222.

[42] J.T. Mitchell-Koch, K.R. Reid, M.E. Meyerhoff, Salicylate detection by complexation with Iron(III) and optical absorbance spectroscopy, J. Chem. Educ. 85 (2008) 1658-1659.

[43] Z.L. Ernst, J. Menas, Complex formation between the $\mathrm{Fe}^{3+}$ ion and some substituted phenols, Trans. Faraday Soc. 59 (1963) 1794-1802.

[44] E. Evans, E. Flávia Moreira Gabriel, W. Karlos Tomazelli Coltrob, C.D. Garcia, Rational selection of substrates to improve color intensity and uniformity on microfluidic paper-based analytical devices, Analyst 139 (2014) 2127-2132.

[45] P. Su, K. Granholm, A. Pranovich, L. Harju, B. Holmbom, A. Ivaska, Sorption of metal ions to untreated, alkali-treated and peroxide-bleached TMP, Cellulose 17 (2010) 1033-1044.

\section{Biographies}

Jiawang Ding received his doctor's degree from Yantai Institute of Coastal Zone Research, Chinese Academy of Sciences in 2011. Presently, he is an Associate professor in this institute. Between 2015 and 2016 he did his postdoctoral research at Åbo Akademi University, Finland. His research interests focus on electrochemical biosensors.

Ning He received the B.Sc. (Chem. Eng.) in 2007 from Qilu University of Technology, Jinan, China. He obtained the M.Sc. (Chem. Eng.) in 2009 from Åbo Akademi University, Turku, Finland. He is currently working at the same university on his Ph.D thesis. 
Grzegorz Lisak obtained his M.Sc. (Chem. Eng.) in physical chemistry in 2007 from Poznań University of Technology, Poland. He obtained his D.Sc. (Tech.) in analytical chemistry in 2012 from Åbo Akademi University, Finland. Between 2013 and 2015 he has been a research fellow at University of Wollongong, Australia and Malmö University, Sweden. Since 2016 he is Assistant Professor at Nanyang Technological University, Singapore. His scientific interests cover electrochemical methods of ion analysis in environmental samples, paper-based sampling, lowering the detection limit of electrochemical sensors, electrocatalysis, functional materials and mitigation technology of $\mathrm{CO}_{2}$.

Wei Qin received his doctor's degree from Nanjing University in 1998. From 1999 to 2003, he did his postdoctoral research at Swiss Federal Institute of Technology (ETH), University of South Carolina and University of Michigan, respectively. He has been working as Professor at Yantai Institute of Coastal Zone Research, Chinese Academy of Sciences since 2006. His research interests include chemical sensors and biosensors for environmental analysis.
Johan Bobacka obtained his D.Sc. (Tech.) degree in 1993 from Åbo Akadem University, Finland. During 1994-1997 he worked as a research scientist at Kone Instruments Corporation (now Thermo Fisher Scientific). He was a senio researcher (1997-2001), Academy of Finland Research Fellow (2001-2006) and Acting/associate Professor (2006-2013) at the Laboratory of Analytical Chemistry, Åbo Akademi University. Since 2006 he has been the Head of the Laboratory of Analytical Chemistry and since 2013 he is Professor in Analytical Chemistry at Åbo Akademi University. His current fields of interest include electroanalytical chemistry, process analytical chemistry, chemical sensors, conducting polymers and electrochemical impedance spectroscopy, with special emphasis on the development of potentiometric ion sensors based on conducting polymers. He has published over 130 peer-reviewed papers, reviews and book chapters. He is the co-inventor of 5 patents/patent applications. His h-index is 33 (Web of Science, November 2016). 